\title{
Nicolás Panotto
}

\section{Teologia como sensibilidade crítica sobre a (hétero)práxis. Desafios hermenéuticos para a teologia da libertação}

\author{
Teología como sensibilidad crítica sobre la (hétero) \\ práxis. Desafíos hermenéuticos hacia dentro \\ de la teología de la liberación
}

\section{Theology as a critical sensibility on (hetero)praxis. Hermeneutic challenges on Liberation Theology}

Resumo: Este artigo tem como objetivo propor uma radicalização da aplicação do método desenvolvido pela teologia da libertação, através da identificação de novas sensibilidades em três elementos centrais em suas hermenêutica, ou seja, o lugar do sujeito, a prática histórica e conceito de Deus libertador. Para este efeito, um diálogo com diversas correntes filosóficas contemporâneas que propõem uma ontologia hermenêutica das categorias de acontecimento e desconstrução de novas mediações epistemológicas, como são estética, o corpo, a poesia, entre outras. Palavras-chave: teologia da libertação, hermenêutica, método - acontecimento, teopoética.

Resumen. Este artículo tiene por objetivo proponer una radicalización de la aplicación del método desarrollado por la teología de la liberación, a través de la identificación de nuevas sensibilidades sobre tres elementos centrales en su hermenéutica, a saber, el lugar del sujeto, la praxis histórica y el concepto de Dios liberador. Para ello, se entablará un diálogo con diversas corrientes filosóficas contemporáneas que proponen una ontología hermenéutica desde las categorías de acontecimiento y deconstrucción, a partir de nuevas mediaciones epistemológicas, como son lo estético, lo corporal, lo poético, entre otras.

Palabras clave: teología de la liberación, hermenéutica, método, acontecimiento, teopoética. 
Abstract. This article aims to propose a radicalization in the application of the method developed by Liberation Theology, through the identification of new sensibilities on three central elements in its hermeneutics: the place of the subject, historical praxis and the concept of the liberating God. For this, we will establish a dialogue with diverse contemporary philosophical approaches that propose a hermeneutic ontology from the categories of event and deconstruction, and from new epistemological mediations, such as the aesthetic, corporality, poetics, among others.

Keywords: liberation theology, hermeneutics, method, event, theopoetics.

En el principio, es la hermenéutica Jacques Derrida

Como manifestó Gustavo Gutiérrez, uno de los principales aportes de la teología de la liberación (TL) ha sido la apuesta por un nuevo método. Una forma de hacer teología que reconoce su contingencia y compromiso histórico, hundiéndose en ella con el objetivo de indagar no sólo sobre las fibras contextuales y transitorias que se tejen en toda matriz bíblica y teológica, sino -principalmente- desde un ferviente llamado evangélico a transformarla. Para ello, su gran jugada epistemológica es ubicar al sujeto oprimido, al pobre, como agente central del quehacer teologal y la interpretación bíblica, es decir, como epicentro hermenéutico que ilumina los procesos revelatorios que se gestan en la historia como único escenario.

Es un método que no se quedó sólo en denuncias de sospecha sino que se concentró en profundizar los diversos niveles de su método. De aquí que la asunción de la historia como campo hermenéutico y los sujetos como epicentro axial del quehacer teológico, conllevó a un estudio puntilloso de las necesarias mediaciones teóricas correspondientes para el análisis. Un abordaje que sin duda trajo muchas discusiones, controversias y tensiones, las cuales se supieron sobrellevar con seriedad, más allá de las consideraciones y valoraciones que podamos hacer sobre las conclusiones alcanzadas.

En síntesis, podemos decir que la TL ofrece un nuevo marco hermenéutico que sin lugar a dudas marcó por siempre el quehacer teológico contemporáneo. Esta afirmación parte de un presupuesto: es precisamente el desarrollo de una clara metodología -con diversos objetos y procesos hermenéuticos, mediaciones teóricas y lecturas socio-antropológicas- lo que ha permitido a la TL establecerse como un marco que ha perdurado a lo largo del tiempo, no sólo desde un tipo discurso particular aún pertinente sino más bien como una propuesta 
hermenéutica provocadora de otros discursos, prácticas, sentidos y cosmovisiones bíblico-teológicas.

Ahora bien, como afirma muy acertadamente Lisa Isherwood (2013, p.13), "la teología nunca ha sido buena para leerse a sí misma". En esta dirección, creemos que la misma TL -al menos en sus primeras generaciones y en los discursos más tradicionales que aún se mantienen vigentes- ha atravesado tensiones internas que tal vez aún no han sido lo suficientemente subsanadas o atendidas, impidiendo así que la propuesta de la TL sea radicalizada desde sus posibilidades constitutivas. Es aquí que planteamos que la TL requiere aplicar y profundizar la mediaciones hermenéuticas de su método para aplicarlas hacia sí misma, como ejercicio de autocrítica y radicalización de sus propuestas. En otros términos, la TL no sólo necesita proponer nuevos contenidos y discursos, sino más bien potenciar la capacidad hermenéutica inherentes a su marco interpretativo.

En este trabajo desarrollaremos algunos elementos que creemos constitutivos de la propuesta hermenéutica de la TL, para luego traer algunas de las críticas que han sido desarrolladas desde el interior de la TL sobre dichos aspectos, y desde allí desarrollar algunas propuestas teológicas que nos lleven por dos caminos: primero, hacia una radicalización de los ejes metodológicos de la hermenéutica de la TL, y segundo, a presentar la necesidad de una autocrítica en torno a la construcción de nuevas sensibilidades que den lugar a tal radicalización.

\section{Hermenéutica en la TL}

Dentro de todos los elementos que forman parte de la hermenéutica en la TL, podríamos mencionar tres ejes centrales: la concepción del Dios liberador, el pobre como sujeto teológico y la historia como escenario de praxis. Estos tres ejes representan tanto los objetos (Dios-Sujeto-Historia) como las claves para los procesos hermenéuticos dentro del método en la TL (es decir, la dinámica entre estos tres objetos representa el punto de partida dentro de la metodología en la TL y de cada uno de sus procesos de interpretación y construcción de sentido).

Para la TL, Dios se presenta como el Dios de la historia, pero no de la "historia sagrada" sino de la "única historia" (Gutiérrez, 1986, pp. 245ss.) donde lo divino irrumpe para desgajar los órdenes opresores que tergiversan los modelos originales de la justa creación cósmica y humana. Es así que la historia, con todas sus luchas y procesos, tensio- 
nes y dinámicas, se instituye como el escenario primordial de revelación, lo que nos lleva inevitablemente a comprender lo divino no como una instancia sobrenatural sino como una fuerza que se devela directa y explícitamente a través de los procesos de liberación. Esta dinámica tensional y emancipadora se convierte en epicentro ontológico para entender tanto la apertura escatológica de lo histórico, como (o desde allí) la emergencia de lo divino a partir de esa inmanencia trascendentalizada puesta de manifiesto (Ellacuría, 1993; 2007)

Esta acción histórica de Dios se traza en procesos socio-políticos y culturales específicos, más concretamente donde se evidencian instancias de opresión y liberación. De aquí que el relato del Éxodo se sitúa como uno de los marcos míticos más importantes de la narrativa bíblico-teológica de la TL, donde la historia se prefigura a partir de la intervención de Dios en la liberación del pueblo de Israel del yugo egipcio (Panotto, 2015). No solo ello, sino también los juegos de poder dentro del pueblo, el reclamo de los profetas por las injusticias de los excluidos y, principalmente, el ministerio de Jesús entre los pobres de Galilea, se comprenderán como principios elementales de la hermenéutica bíblica liberacionista.

Aquí vemos el siguiente elemento significativo: el lugar del pobre como sujeto teológico. La opción por los pobres no es una opción simplemente ideológica, pragmática o política. Es una opción teológica. Como afirma Gustavo Gutiérrez: "El pobre debe ser preferido no porque sea necesariamente mejor que otros desde el punto de vista moral o religioso, sino porque Dios es Dios." (Gutiérrez, 2002, pp.13-14) Es a partir de esta iniciativa divina que el pobre se transforma en un sujeto hermenéutico, ubicándose así en epicentro de revelación, no solo como "lente" de interpretación de las Escrituras sino también de los propios dogmas cristianos, las practicas de espiritualidad, las dinámicas socio-políticas y los procesos eclesiológicos que constituyen la metodología de la TL (Vigil, 1991).

Por todo esto la teología es definida desde la TL como "reflexión crítica sobre la praxis" (Gutiérrez, 1986, pp.72-88), es decir, como una resignificación en torno a la acción de Dios a partir del compromiso histórico y liberador con los pobres de la historia. Este marco se presenta como elemento "pre-teológico", o sea, como gesto previo que lleva a replantar las lecturas bíblicas, las prácticas creyentes, los modelos de iglesia y los propios dogmas. De aquí que el método en la TL es bosquejado de una manera mucho más amplia que la teología 
clásica -que podríamos definir muy someramente como racionalista, abstracta y poco articulada, al menos explícita y metodológicamente, con elementos contextuales-, donde -siguiendo a Clodovis Boff (1980)tiene dimensiones tanto profesionales como pastorales y populares.

Volviendo a lo planteado inicialmente, creemos que la relación entre estos tres objetos -Dios, sujetos(s) e historia- son elementos centrales para definir la propuesta hermenéutica de la TL, tanto en términos dogmáticos como bíblicos. Primero, porque es una hermenéutica que ubica la historia como escenario donde lo divino es revelado (por ende construido, descrito e interpretado en tanto Ser), lo cual implica ubicar y analizar los procesos, tensiones, dinámicas, marcos de sentido, discursos, prácticas institucionales -presentes tanto en el texto bíblico como en el ámbito del sujeto interpretante-, entre otros elementos, para exponer las nociones sobre lo divino y su economía. Segundo, porque es una hermenéutica cuyo locus se coloca en el contexto y las caracterizaciones constitutivas e identitarias de un sujeto, que no sólo es receptor sino agente activo (praxis) Y tercero -aunque no último-, porque es una hermenéutica que parte de un cuestionamiento y deconstrucción de la propia ontología divina, la cual asume, interpela, tensiona y desafía los procesos de dicha historia, entendidas todas ellas como epicentros de revelación.

\section{Críticas, desencantos y reduccionismos}

Como dijimos, el establecimiento de un fundamento hermenéutico con la estructura que planteó la TL, permitió que dicho paradigma prevalezca como un método extendido en el tiempo, que pudo responder a diversos contextos y circunstancias, y que se instituyó como el punto de partida de un conjunto de expresiones bíblico-teológicas particulares. Pero cabe reconocer también que dicha diversidad de voces no provino solamente desde los contenidos desarrollados por la TL, sino más bien por el movimiento que sus ejes hermenéuticos activaron a partir de distintos sujetos, cosmovisiones sobre la historia y sobre lo divino. En este sentido, podemos decir que los elementos hermenéuticos del método en la TL cuestionaron, desafiaron y superaron muchas de las propuestas y discursos particulares a las que llegó, para dar lugar a expresiones que, más allá de identificarse con las raíces de la TL, dieron lugar a otras identificaciones, las cuales terminaron minando desde adentro su matriz discursiva. 
A lo largo de la historia de la TL encontramos varias voces surgidas desde su propio seno, que han expresado fuertes cuestionamientos hacia algunos de sus contenidos teológicos, o sobre sus reduccionismos con respecto a los elementos hermenéuticos de su método. Muchas de estas críticas han ido orientadas sobre alguno de los tres ejes que hemos desarrollado hasta aquí.

Por ejemplo, Ivone Gebara (2000, pp. 50-69) habla del carácter esencialista, antropocéntrico y androcéntrico que aún mantiene la idea de Dios Liberador en la TL. Más allá de que la autora valora este paradigma teológico y su aporte en la redefinición de lo divino, esboza que la comprensión del Dios Creador, Señor y controlador de la Historia tal como la TL lo desarrolla en muchos de sus abordajes, propone una imagen clausurada de lo divino que lo mantiene dentro de ciertas cosmovisiones clausurantes, sea con respecto a otros modos de ver la historia como a la inclusión de nuevos sujetos axiológicos, lo cual posibilitaría desarrollar nuevos discursos teológicos a partir de otras experiencias históricas. En la misma línea, Hugo Assmann (2000, p.115) llega a la siguiente frase lapidaria: "la TdL no replanteaba a fondo los temas clásicos de la teología, y en este sentido era conservadora. Un ejemplo llamativo es el del supuesto carácter intocable del 'Dios obvio' como un Ente indiscutible, incluso como imagen popular internalizada de un dueño y señor absoluto de todas nuestras circunstancias".

El segundo aspecto tiene que ver con la noción de sujeto, especialmente con las implicancias de la opción por los pobres. Una de las grandes críticas en este campo ha sido desarrollada por Marcella Althaus-Reid, quien en todos sus trabajos indica que la noción de pobre dentro de la TL expresa una cosmovisión rígida sobre los sujetos -más particularmente, entre pobres varones y pobres mujeres- sin tener en cuenta una hermenéutica de la sospecha en términos de sexualidad (Althaus-Reid, 2005, pp. 29-34), con todas las implicancias que ello tiene para identificar otras instancias de opresión como también de liberación desde la experiencia de los y las oprimidos/as.

Por su parte, Hugo Assmann (2004) cuestiona no sólo el reduccionismo en torno a la comprensión del pobre como un sujeto único y cuasi metafísico de la TL, sino también a otras propuestas -como las de Franz Hinkelammert (1998) y Jung Mo Sung (2005)- que han complejizado dicha noción -especialmente desde la idea de sujeto- pero que aún parten de intuiciones demasiado estructurales y suturadas de lo identitario (y de los procesos de identificación), al no considerar 
las ambivalencias y heterogeneidades que se gestan al comprender a las personas a partir de los procesos cotidianos, la corporalidad, los deseos y las pasiones. En otros términos, persiste una idea abstracta, patriarcal y economicista del sujeto-pobre, que no considera su cuerpo, su cotidianeidad, su sexualidad, sus relaciones y sus pasiones.

Por último, también encontramos algunas discusiones con respecto al método de la TL, especialmente en torno a los tipos de mediación teórica. Ya sabemos que el uso del marxismo ha sido uno de los aspectos que más discusión ha traído, aunque tal vez podríamos afirmar que ello no representa el problema de fondo. Más bien, el método de la TL ha caído bajo ciertos esencialismos epistemológicos (como son una definición poco complejizada del sujeto, una comprensión mecanicista de la historia y una teología que no ha ido a fondo sobre algunos dogmas), desde los cuales se propusieron categorías analíticas reduccionistas, y con ello cosmovisiones sobre la historia y las dinámicas socio-políticas que no alcanzan a adentrarse analíticamente con la profundidad necesaria sobre los turbulentos y grises abismos del contexto. Esta clausura no se debe tanto al uso del marxismo en sí, como a la carencia de cuestionamiento para deconstruir nociones elementales, sin complejizar las mediaciones analíticas desde estudios de la heterogeneidad, de la corporalidad, la sexualidad y la dimensión estética de las construcciones sociales.

Un ejemplo de este cuestionamiento lo vemos en Juan Luis Segundo, quien ha trabajado sobre la necesidad de una profundización en las mediaciones teóricas dentro de la TL. En una de sus críticas a la matriz maniquea de la TL, leemos lo siguiente (Segundo, 1983, p.272):

Podríamos decir, sin temor a errar, que ésta [la teología de la liberación] creyó
constituirse desplazando el acento de una salvación -considerada ultraterrena- a
la humanización del hombre, liberándolo de todas las opresiones que, desde su
interior o desde su entorno, en el plano individual o en el colectivo, lo infantiliza-
ban y alienaban. Pero ocurrió que a esta nueva acentuación se llevó la misma vieja
epistemología teológica. En otras palabras, se trasladó a la temática liberación
un tipo infantil, linear y maniqueo. El bien y el mal, la gracia y el pecado, habían
cambiado de nombre o tal vez de localización. Ahora se llamaban liberación y
opresión, revolución y desarrollo. Pero seguían oponiéndose de la misma manera
simplificada y absoluta.

\section{Tocando las fibras de nuevas sensibilidades interpretativas}

Frente a estas críticas, queremos proponer una reflexión de doble vía, es decir, que encare la legitimidad de cada una de ellas, pero que 
a su vez reivindique la tradición metodológica de la TL a través de la profundización de sus elementos constitutivos. El primer elemento a destacar es la necesidad de una nueva sensibilidad. El uso de este término no es fortuito. Como hemos visto, muchos de los cuestionamientos a la TL van en dirección a las simplificaciones y reduccionismos de sus postulados: partir de una comprensión clausurada de los sujetos, de una visión estructuralista de la historia, de utilizar mediaciones teóricas maniqueas y esbozar una visión de Dios abstracta, no en términos supranaturales sino precisamente históricos. De aquí la necesidad de nuevas sensibilidades, es decir, de poner en juego otras mediaciones, como son el cuerpo, las pasiones y afectos, la atención a las líneas de fuga y ambigüedades de los procesos sociales, que distan de ser sólo contingencias, sino instancias determinantes para la pluralización, crítica y heterogenización de la teología.

El segundo elemento tiene que ver, como ya lo hemos planteado al inicio, con la necesidad de que los procesos hermenéuticos propios del método de la TL sean aplicados para una crítica hacia adentro de su paradigma y discursos particulares. Aunque esto pueda sonar contradictorio con lo desarrollado hasta aquí -especialmente a lo concerniente sobre la importancia de los elementos hermenéuticos dentro del método de la TL-, nos referimos más concretamente al hecho de que muchas veces los ejes hermenéuticos que propone la TL son utilizados pragmáticamente y no ontológicamente; es decir, como procesos de argumentación apologética -o sea, para llegar a ciertas verificaciones establecidas a priori- antes que ser entendidas como procesos que resignifiquen y empujen las fronteras de la identidad constitutiva de la TL y de cada uno de sus elementos. En este sentido, la empresa que nos proponemos es abordar los puntos que hemos identificado en esta hermenéutica, desde otras mediaciones que nos ayuden a profundizar su potencial hermenéutico desde el interior de la TL.

\section{Hacia una ontología hermenéutica del acontecimiento teológico}

Un primer paso en este replanteo es ubicarnos sobre una comprensión más amplia de lo propiamente hermenéutico. En este caso, deseamos hacerlo desde dos elementos particulares. En primer lugar, desde la idea de ontología hermenéutica. Este concepto ha sido elaborado desde diversas corrientes, aunque posee sus raíces en la filosofía heideggeriana, y luego cobró más fuerza con discípulos como Hans- 
-Georg Gadamer y Gianni Vattimo. Este último define la ontología hermenéutica a partir de tres características: "el rechazo a la objetividad como ideal del conocimiento histórico...; la generalización del modelo hermenéutico a todo conocimiento, histórico o no; la lingüisticidad del ser" (Vattimo, 1986, p.25)

Nuestro deseo no es desarrollar esta propuesta filosófica, ya que no es el lugar para hacerlo, sino simplemente resaltar dos aspectos importantes que pueden representar un aporte a la resignificación que queremos formular en este trabajo. En primer lugar, dicho marco subraya que la hermenéutica no es simplemente una herramienta que media entre una masa amorfa de elementos y un conjunto de dinámicas que pretenden exponer las prácticas interpretativas de fondo, sino es más bien el campo constitutivo del arjé de cualquier posicionamiento ideológico, cosmovisional o práctico. En este caso, la dinámica hermenéutica, es decir, los procesos de construcción de sentido e interpretación, son constitutivos de las fibras mas íntimas del quehacer bíblico-teológico y no un objeto externo que analiza fundamentos dados. Por este motivo, hablar de la teología como ontología hermenéutica significa no sólo ver los tipos de cosmovisiones que se juegan "detrás" de sus contenidos particulares sino desde las instancias de tensión, deconstrucción y resignificación de los discursos que le dan presencia, figura que no sólo se vincula con el "lenguaje" sino con toda práctica de construcción de sentido, las cuales se van transformando constantemente. ${ }^{1}$

El segundo elemento a resaltar, el cual está relacionado con lo antedicho, es que la ontología hermenéutica es intrínsecamente política. Como afirman Vattimo y Zabala (2012, p.126): “Más que filosofías descriptivas, la interpretación supone a menudo un llamamiento a favor de la emancipación, lo cual es políticamente revolucionario; en otras palabras, se opone al estado de cosas objetivo. Por eso la hermenéutica ha sido siempre la espina dorsal latente de las revoluciones culturales contra quienes poseen el poder, es decir, de los movimientos mas fecundos contra la verdad impuesta." Aquí podemos retomar lo abordado anteriormente y aseverar que el poder liberador y político de la propuesta bíblico-teológica de la TL reside no sólo en la construcción

Aquí nos alejamos de la centralidad que algunas corrientes posestructuralistas le dan al aspecto lingüístico como elemento central de la hermenéutica, tal como vimos en la definición de Vattimo. Nos concentramos más bien en la idea de construcción de sentido, la cual va mucho más allá del lenguaje y se acerca a la idea de praxis desde una definición más amplia, incluyendo los elementos no humanos y la intersubjetividad de los objetos (Harman, 2015; Latour, 2005) 
de un tipo de discurso particular en torno a estas nociones -liberación, política, emancipación, opresión, etc.- sino en el ejercicio hermenéutico que invita a cuestionar los lugares -eclesiales, teológicos, sociales, individuales, económicos, etc.- como posicionamientos únicos y absolutos, para abrir nuevos marcos de lectura y praxis histórica.

Esto se relaciona, a su vez, con una teología del acontecimiento, como ha propuesto John Caputo (2010). La noción de acontecimiento ha sido desarrollada por varios filósofos, partiendo por Jacques Derrida (2013), y pasando por Gilles Deleuze (1994), Alain Badiou (2007) y Slavoj Žižek (2014). Esta categoría intenta ubicarse como un interludio nubloso (o un "frágil absoluto", en palabras de Žižek) entre los sentidos de representación (donde todo puede ser definido de manera estricta) y el vacío (donde nada puede contener un sentido fijo). De esta manera, los acontecimientos constituyen símbolos, situaciones y discursos, que están atravesados por ambas instancias -la representación y el vacío-, haciendo de su constitución ontológica un marco ambivalente, y de allí polivalente; es decir que pueden ser representados a través de sentidos específicos, pero el vacío ontológico que las atraviesa hace de su situación particular algo pasajero, cuestionable y con posibilidades de ser algo distinto.

El acontecimiento puede encontrarse en la situación, aunque no pertenece a ella. Tampoco es vacío aunque está al borde de él. Es, más bien, el minimum de la estructura de la representación. Los acontecimientos fundan las situaciones, ya que están continuamente interrumpiendo los procesos combinatorios de lo Múltiple, lo diverso, lo heterogéneo, como categorías ontológicas (Panotto, 2012). En el acontecimiento se constituye la diferencia. Pero no la diferencia como simple descripción de lo diverso. Es, en palabras de Ángel Gabilondo, la reivindicación del poder hacer la diferencia frente a una diferencia insignificante con objetivos simplemente descriptivos, cuantitativos y pragmáticos (Gabilondo, 2001, p.14).

El acontecimiento, entonces, permite realizar una lectura de las circunstancias (discursivas y materiales), no como marcos clausurados y absolutos, ni tampoco como matrices tendidas en una nada sin posibilidad de afirmación, sino como instancias que contienen especificidades interpretativas, aunque sin clausurar su sentido y praxis, sino más bien ampliándolas hacia una diversidad de conceptos, prácticas y cosmovisiones.

Desde esta perspectiva, la teología no se manifiesta en la sutura de la representación (discursos, símbolos y prácticas determinadas) 
ni en la carencia de un locus, sino en una comprensión de la ontología divina como aquella que se posa y a la vez se mantiene inquieta para seguir hacia otros lugares, y así despertar nuevos locus de sentidos. Parte de un contexto y a la vez lo presiona para crear fisuras hacia nuevos escenarios. Los acontecimientos teológicos son provocaciones y promesas que inscriben los lugares y las identidades en un de-venir de lo divino como de-venir de lo teológico. Desde esta perspectiva, podríamos plantear que los sentidos del "Dios liberador", "la historia una", "la opción por los pobres", son acontecimientos dentro del método en la TL, donde el sentido de estas demarcaciones se posa, pero no se clausura en un tipo de definición, sino que imprimen una apertura inherente como búsqueda de otras epistemologías.

De aquí queremos resaltar, una vez más, la importancia hermenéutica de la TL, recalcando que los elementos fundantes de su método no deben comprenderse sólo como discursividades clausuradas en tipos de representación sobre lo divino, los sujetos o la historia, sino como marcos acontecimentales a partir de los cuales se pluralizan sentidos y prácticas. Esto permite la inclusión de otras mediaciones teóricas, otros sujetos, otras cosmovisiones de la historia y, principalmente, otros modos de definir a Dios.

\section{Alteridad, historia y subjetividad(es)}

Uno de los temas relacionados a esta resignificación de los procesos hermenéuticos en la TL es el sentido de alteridad y trascendencia como categorías ontológicas. La ontología hermenéutica como marco de quehacer teologal implica considerar la alteridad, la diferencia y la pluralidad como puntos de partida de su método. En esta línea, cabe traer la reflexión que realiza Antonio González (1993) sobre el significado filosófico de la TL. Este teólogo identifica la opción por los pobres y la praxis histórica como dos elementos centrales en dicha propuesta teológica, que pueden ser ubicados como aspectos que representan una dimensión más bien filosófica, y no sólo como temas dispersos que dicha propuesta desarrolla. González formula que la noción de praxis histórica -teniendo en cuenta la concepción dentro de la TL sobre la historia como espacio revelatorio- debe ser el marco a partir del cual se inscriba la noción de sujeto, con el objetivo de que ella no caiga en una definición suturada, metafísica y a priori de los agentes. 
Más bien -remitiendo a Jon Sobrino- González habla de la densidad metafísica de la propia historia, como instancia que atraviesa a los sujetos. De aquí, la inscripción de los sujetos en la historia es entendida como epicentros de trascendentalidad; pero no una trascendentalidad anclada en lo objetivo y lo subjetivo como polos contrapuestos sino -siguiendo a Zubirí- en una alteridad donde la realidad es actualizada en la inteligencia sentiente, es decir, en el ágape que cimenta la existencia humana, donde las comprensiones racionales son cambiadas por un epicentro de intersubjetividad (corporal y afectiva).

Esto se relaciona con el trabajo de Ignacio Ellacuría sobre la filosofía de la historia y la salvación. La alteridad de lo divino no es un elemento extra-histórico sino intra-histórico, por lo que se produce un movimiento de doble vía: la historia se define desde la apertura ontológica que produce la revelación de Dios, y lo divino se representa a partir de la tensión inmanente-trascendente en la propia historia. Por ello, Ellacuría (1993, pp.328-329) enfatiza “[...] en ver la trascendencia como algo que trasciende en y no como algo que trasciende de, como algo que físicamente impulsa a más pero no sacando fuera de; como algo que lanza, pero al mismo tiempo retiene [...] Puede separarse Dios de la historia, pero no puede separarse de Dios la historia [...] La trascendencia de la que hablamos se presenta como histórica y la historia se presenta a su vez como trascendente [...]".

Las nociones de alteridad y trascendencia profundizan y radicalizan los presupuestos de la TL, desde los tres objetos hermenéuticos que mencionamos. Primero, redefine la ontología de lo divino y su revelación, enmarcándola más bien a partir de la tensión que se produce en la historia desde los procesos de encuentro y ausencia, y no en los extremos de una trascendencia supra-natural o una inmanencia clausurante. Segundo, inscribe la cuestión del sujeto no sólo en una especie de marco depositario ni de agente absoluto sino como epicentro de diferenciación de sentidos. Tercero, hace de la historia un campo que potencia una pluralidad de prácticas y no un marco clausurado de cosmovisiones. Aquí se puede ubicar la diferenciación que establece Nelson Maldonado-Torres (2005, p. 57) sobre el hecho de que la teología de la liberación debería pensar "no sólo en términos de ortodoxia y ortopraxis sino en términos de heterodoxia y heteropraxis". 


\section{Teo-poética y crítica poscolonial}

Como hemos mencionado, en este artículo utilizamos la idea de sensibilidades de manera intencional. Las limitaciones de la propia TL o, en otros términos, la necesidad de radicalizar varios elementos de su método, remiten a la exigencia de tener una mayor sensibilidad sobre las complejidades, cotidianeidades, pasiones y sentimientos que se ponen en juego a la hora de discernir la acción de Dios, los procesos de la historia y los modos en que se constituyen y actúan los sujetos. Por ello, lo estético, el arte y lo corporal, deben ser considerados como marcos elementales de un ejercicio hermenéutico perceptivo a las dinámicas existenciales.

Por ello hablamos de la necesidad de profundizar en una teo-poética, es decir, de resaltar la dimensión poética de lo teológico como camino para habilitar una hermenéutica desde instancias que permitan tomar en cuenta los complicados vericuetos de la vida, los cuales van mucho más allá de lo que lecturas matemáticas del campo social ofrecen. Conlleva dejar de lado los reduccionismos de abordajes racionalistas y estructuralistas que han reinado en la TL, y que terminaron, como hemos argumentado, en lecturas homogeneizantes sobre Dios, la historia y los sujetos. Por ello, necesitamos considerar la dimensión radical y crítica -a nivel bíblico-teológico y socio-político- que posee un abordaje sensible a la poética, lo corporal y lo estético, tanto de los discursos como de la praxis.

Es aquí donde podríamos traer la noción de experiencia desarrollada por María Zambrano, una de las filósofas que más énfasis ha dado sobre la importancia de construir una razón poética para la filosofía (Zambrano, 2011) En la misma línea que Deleuze (2000), quien aborda la relación intrínseca entre diferencia y repetición -donde las instancias de diferenciación siempre se gestan en cualquier proceso de institucionalización o construcción de sentido-, Zambrano plantea la experiencia humana como una vivencia fuera de los cálculos y las leyes, aunque se inscribe en ellas como campos inevitables. La experiencia, entonces, es un a priori a la teoría pero sin salir de ella. De todas formas, "ha sido indispensable una cierta aventura y hasta una cierta perdición en la experiencia, un cierto andar perdido el sujeto en quien se va formando. Un andar perdido que será luego libertad" (Zambrano, 2011, p.68) 
De aquí, podríamos afirmar que al referirnos a la experiencia de los sujetos teologales debemos remitir también a esa dimensión de "pérdida", como los momentos de falta de claridad racional, de inconsciencia, de ambigüedad y hasta de contradicción, a través de los cuales todo sujeto atraviesa frente a cualquier instancia de construcción de sentido. Dichos elementos distan de ser contradictorios con una ontología hermenéutica. Por el contrario, refieren a una mayor sinceridad respecto a las dinámicas reales que viven y atraviesan los sujetos interpretantes.

Esto podría vincularse con una concepción fundante dentro de la TL, a saber, la idea de praxis como elemento "pre-teológico" (Gutiérrez, 1986, pp.80-84; Boff, 1980, pp.35-64). Más allá de algunos cuestionamientos que podríamos sostener en torno a cierto reduccionismo presente en esta afirmación -ya que ninguna praxis deviene como tabula rasa en términos teológicos-, la idea de experiencia como elemento "previo" a la construcción teológica implica considerar todos los elementos estéticos y corporales que entran en juego como aspectos constitutivos del sujeto. La noción de praxis en la TL muchas veces se presenta de manera abstracta, a partir de definiciones homogéneas y desde un discurso de "razón política" que apela a una consciencia suturada por parte de los sujetos, lo cual muchas veces deja de lado las ambivalencias, contradicciones, pasiones, afectos, relaciones corporales y experiencias estéticas que deben ser consideradas a la hora de analizar el lugar de las personas y las dinámicas sociales dentro de los procesos hermenéuticos.

No sólo necesitamos deconstruir los modos de entender las experiencias de los sujetos sino también el marco de sus acciones. De aquí la advertencia de Eugenio Trías sobre la necesidad de liberarse de la tecnociencia para alcanzar una crítica radical sobre los fundamentos metafísicos que contaminan nuestras epistemologías (Trías, 1994) Por ello, dice este filósofo, la salida se encuentra en otorgar un mayor énfasis a la poiesis, es decir, a una definición artística y estética sobre la tejné. Esto no significa descartar por completo la dimensión metafísica como marco ontológico sino ubicarla en el intersticio, o sea, en su movimiento inherente entre lo racional y lo irracional, lo dado y el de-venir. En otras palabras, en su intrínseco lugar en la frontera de los sentidos. Requerimos recuperar la "dimensión limítrofe" del logos, donde la palabra, el sentido y la praxis se ubican como instancias creativas que van más allá de conceptualizaciones categóricas. Y tal como hemos mencionado, esta apertura poiética del sentido inscribe en sí misma 
una dimensión socio-política al desafiar y perturbar los fundamentos sobre las representaciones establecidas.

Por todo esto, "el desafío que interpela a la teología es el lugar que otorga al trascendental bello como experiencia de apertura y trascendencia" (Mattera, 2010, p.250) La dimensión estética, corporal y artística de lo teológico no implica clausurar su quehacer, una vez más, a ciertas fronteras a priori o segmentadas que se apartan de otras experiencias intrínsecas a la hermenéutica, tales como lo socio-político, lo cultural, lo económico, lo científico, etc. Más bien, resalta aquellos elementos inherentes a la existencia histórica y a la constitución de los sujetos, que se ponen en juego a través de los gestos del cuerpo, la imaginación, los innumerables tipos de relación con el cosmos y la humanidad, y que simbolizan los elementos fundamentales de cualquier proceso hermenéutico, aunque muchas teorizaciones racionalistas y cientificistas quieran ubicarlo en un lugar secundario o nulo.

Hablar de teo-poética es dar énfasis a la trascendencia y la alteridad de lo divino a partir del empoderamiento de los sujetos desde una clave liberadora, ya que ello implica incluir y reconocer las diversas formas en que participan, intuyen y describen el Misterio divino en tanto movimiento constante de revelación y praxis histórica (Rivera, 2007) La teo-poética significa trascender lo "obvio". Por ello, es supra teológica (LoPresti, 2013, pp. 81-82), en línea con lo desarrollado a partir de Zambrano. Es lo que nos advierten mucho teólogos y teólogas contemporáneos (Schneider, 2008, pp.107-126; McFague, 1994, pp. 63-107) sobre el hecho de que la ontología teológica no puede estar separada de la poesía y lo mitológico, inclusive de lo lúdico (Alves, 1976, 1982; Geraldina Cespedes, 2014; Panotto, 2016a, pp. 79-98) Como concluye Catherine Keller (2003, p. xviii), "si el discurso teológico quiere vivir, debe hablar entre los intersticios de las densidades históricas del texto y sus esperanzas creativas".

La teo-poética inscribe también una dimensión crítica en clave socio-política. La teoría y teología poscoloniales han aportado a dicha comprensión, resignificando varios de estos elementos en clave crítica. Sostiene que los contextos de opresión -que aún no han dejado de lado su impronta colonial, si analizamos con profundidad las dinámicas geopolíticas imperantes- distan de ser suturados y clausurados sino que contienen incontables fisuras que socavan desde adentro su estabilidad, a partir de la diferencia colonial impresa sobre los individuos y las comunidades (Bahbah, 2002) Los sujetos no son agentes 
oscurecidos bajo lógicas omnímodas sino que siempre subvierten los órdenes, pervirtiendo las normatividades a partir de las vivencias cotidianas y a través de gestos que, aunque cuantitativamente pequeños y muchas veces no tomados en cuenta, ponen en jaque y resisten los despliegues coloniales de las lógicas opresoras sobre el ser, el saber y los cuerpos, a través de la resignificación de símbolos, la reapropiación de industrias culturales, la tergiversación de los mecanismos de consumo y mercado, etc.

Son las tensiones que se gestan dentro del abismo colonial (Yountae, 2016), donde las profundidades incontrolables y desconocidas de la cotidianeidad humana y cósmica inscritas en la propia presión colonial, empujan la emergencia de nuevos mundos, nuevos sentidos, nuevas epistemologías. Es comprender que donde se gesta la diferencia, se originan (nuevos) comienzos. Por eso, la teo-poética es una propuesta teológica theomática (Keller, 2003, pp. 3-24) y poscolonial, donde la dinámica cósmica se entiende como gestación a partir de y en el caos, y desde las profundidades del misterio de la historia, a partir de las cuales los sujetos y las cosmovisiones disruptivas emergen como fuerzas divinas, a partir de la incontrolable experiencia intersubjetiva (Panotto, 2016b).

En resumen, la dimensión teo-poética nos lleva a enfatizar que la construcción de nuevas sensibilidades en torno a la definición de la economía divina, el lugar de los sujetos hermenéuticos y la heteropraxis histórica, vienen de la mano de la inclusión de elementos vinculados con otros marcos epistemológicos, donde entran en juego las dimensiones corporales, estéticas, artísticas y poéticas. La consideración de dichos elementos nos permitirá evidenciar otras formas de concebir las relaciones sociales, los movimientos de los sujetos, y por ende, las maneras de elaborar discursos teológicos, no a modo de "embellecer" de forma naíf el discurso teológico -tal como lo consideran prejuiciosamente algunos lectores de esta propuesta-, sino como una forma de evidenciar las construcciones de sentido que se gestan en contextos de ambivalencia, complejidad y originalidad, a partir de los cuales se empoderan y revaloran las prácticas cotidianas de los sujetos como instancias de cuestionamiento creativo frente a los sentidos hegemónicos que fundamentan las lógicas de opresión. 


\section{La Biblia como locus acontecimental}

Decíamos que el acontecimiento refiere a un marco que funda y a la vez atraviesa las situaciones y representaciones en tanto espacialidades y prácticas concretas, con el objetivo de abrir su sentido. El acontecimiento es la nominación o universo simbólico que se mueve al borde del vacío, por lo cual entra y sale de cada situación, para fundar nuevas. Dicha dinámica potencia las prácticas y discursos particulares, pero articulándolas en un espacio que las deconstruye y redefine. Esto lleva a cuestionar la universalización de cualquier representación, reinscribiéndola dentro de un espacio más amplio que multiplique universos de sentido y prácticas políticas.

Desde esta perspectiva, queremos proponer que la potencia hermenéutica -y por ende socio-política- del texto bíblico, reside precisamente en habilitar una lógica acontecimental en torno a las definiciones de Dios y la (hetero)praxis de los sujetos creyentes que lo interpretan. Juan Luis Segundo nos ayuda a profundizar esta idea a través de la relación que hace entre los conceptos de sentido (círculo hermenéutico), verdad y dogma. Ya en su definición de círculo hermenéutico ofrece una alternativa para la lectura de los textos bíblicos, donde su interpretación es vinculada a un marco ideológico y un contexto social determinado (Segundo, 1975, pp.11-45). Segundo enfatiza en comprender la Biblia, no como un cúmulo de verdades absolutas sino como un texto donde se cristalizan innumerables historias, que son retomadas constantemente para ser resignificadas en la búsqueda de "la verdad".

En otras palabras, la centralidad del texto bíblico se encuentra en ofrecer un espacio de sentido polivalente que permita la redefinición del lugar del sujeto creyente. En sus palabras: "Un pueblo, lo mismo que una iglesia, no se identifica nunca por la exactitud de un hecho material, sino por un 'sentido' constitutivo, por algo en lo que se "cree" (Segundo, 1989, p.72). Para Segundo, esta apertura de sentido tiene que ver directamente con la manera en que los sujetos actúan en la historia para redefinirla. "Lo que en primer término importa para el mundo del sentido es su función literaria: que sean claros y elocuentes en mostrar un esquema de puntuación que permita, en lo sucesivo, construir una 'experiencia', abriendo así el espacio para saltar más humanamente al plano de lo histórico.” (Segundo, 1989, p.73)

De esta manera, la Biblia es comprendida por Segundo como un texto que evidencia la búsqueda constante por parte de grupos huma- 
nos que reinterpretaban sus historias a la luz de vivencias concretas y con el objetivo de buscar la "verdad" adyacente, pero no como un marco concluyente y absoluto sino como un horizonte de búsqueda cuya función es mantener abiertas las fronteras del sentido, precisamente para habilitar el movimiento, la pluralidad de discursos y la diversidad de prácticas. En otras palabras, se produce un proceso dialéctico donde, por un lado, la búsqueda por la verdad lleva a ir más allá de las particularidades históricas, y por otra, a comprender la entidad ontológica de la verdad desde dichas particularidades múltiples. En términos de Segundo: "Por encima de 'la' historia de la salvación había que establecer una metahistoria, porque resultaba que, en lugar de 'una' historia de la salvación, la Biblia volvía una y otra vez sobre los mismos sucesos, interpretándolos en cada época de manera diferente, de acuerdo con las necesidades igualmente diferentes de Israel. Y entre esas 'historias' había que hallar 'la verdad'” (Segundo, 1989, p. 86-87).

Aquí, entonces, la importancia del término dogma en Segundo, entendido como la convergencia entre sentido y experiencia; o sea, a partir de la búsqueda por la verdad que atraviesa la situación histórica desde donde se parte, no anulándola sino incluyéndola. En sus palabras (Segundo, 1989, p. 98):

\begin{abstract}
Recordará el lector que el interés del "dogma" no residía en penetrar en una región teológica enrarecida y exclusivamente abierta a un determinado grupo de mortales, sino en puntuar el flujo de los acontecimientos de manera tal que se percibiera su "sentido". Las secuencias similares percibidas como resultado de ese aprendizaje, depositadas en una memoria activa -esa memora organizadora de conocimientos que llamamos "experiencia" en un sentido existencia, no científico- capacitan así al hombre para prever los acontecimientos frente a la significación y los valores que el ser humano pretende introducir en aquéllos.
\end{abstract}

Es en esta apertura dogmática que reinscriben las historias y experiencias donde encontramos el potencial hermenéutico del texto bíblico. En otros términos, en su capacidad para deconstruir sentidos, prácticas y cosmovisiones. John Leavey (1982) nos da algunas pistas en esta línea, proponiendo una hermenéutica bíblica a partir de los aportes de Jacques Derrida. El autor comienza diciendo que la deconstrucción puede resumirse en la siguiente frase: en algún sentido. Es re-leer la filosofía "en algún sentido", lo que permite plegar y replegar el texto continuamente. La deconstrucción es interna al discurso. Convive en la misma esencia del supuesto objeto a deconstruir; más aún, ella es parte de su constitución ontológica. Esto significa que la "interioridad" 
de este objeto o discurso no es auto-suficiente, como un interior sin exterior, un interior sin interior, o un exterior sin interior.

La deconstrucción lleva a la guerra. Esto significa que los objetos, los textos, las interpretaciones se encuentran en continua puja por ser delimitados frente al encuentro con la otredad. Es así que el texto se "destruye" y es "ejecutado". La deconstrucción analiza la gran "maquinaria de oposiciones", lo que el texto programa, lo que programa al texto y todo aquello que pone sobre la brecha el mismo programa. El texto es ubicado intertextualmente con otros. La lectura derrideana propone hacer que aquellas "preguntas retóricas" suspendan su lógica y abran el texto hacia una infinidad de posibilidades de sentido. Saca de su lugar de seguridad la escritura de Dios y la del ser humano. Por todo esto, la deconstrucción no es simplemente una herramienta para la crítica literaria ya que su propuesta es plenamente filosófica.

Leavey sostiene que la deconstrucción deber ser comprendida entre el deseo y el decir dentro de una red de significados. Más que una técnica de lectura, orienta tal acto abriendo cierta orientación, implicando el deseo y el decir del interprete, la propia significación que otorgamos, al significado del texto. De aquí, podemos comprender la estrategia general de la deconstrucción en dos pasos. El primero es la inversión, donde la jerarquía del texto y los intertextos son "dados vuelta". El segundo es desplazar o reinscribir la nueva jerarquía invertida, para que la nueva jerarquía no funcione como la antigua. Este segundo paso es llamado desplazamiento, trasgresión o reinscripción. El primer paso es ejecutado continuamente; nunca se realiza de una vez por todas. El segundo es lo que Derrida utiliza para mantener en balance la antigua y nueva jerarquía.

Con respecto a su propuesta de análisis textual, Derrida llama indecibles a aquellas "unidades de simulacro", propiedades verbales "falsas" que no pueden ser incluidas en las oposiciones binarias filosóficas, pero que permanecen allí, inhabitando tal oposición, resistiéndola y desorganizándola. La deconstrucción implica el desmantelamiento de algo en "componentes discretos", existiendo siempre la posibilidad de poner las piezas juntas nuevamente. Eso no quiere decir que ella sea solamente un ejercicio de de-segmentación sino una técnica que permite resurgir aquellos elementos que siempre han estado allí.

La noción de deconstrucción nos ayuda a proyectar el potencial hermenéutico y dogmático del texto bíblico, al permitirnos superar reduccionismos binarios o lecturas semióticas estructuralistas, e iden- 
tificar los valores de la pluralidad y la alteridad inherentes a la Biblia, no desde la imposición de un conjunto de categorías ad hoc (como a veces se denuncia a las lecturas posmodernas y su supuesto intento de "forzar" el sentido del texto, como si existiera un marco establecido al cual remitirse) sino desde el reconocimiento de sus "componentes discretos" y "unidades de simulacro" como aperturas presentes dentro del mismo texto (los cuales no son simplemente contingencias lingüísticas sino referencias a experiencias históricas concretas), que habilitan inversiones y desplazamientos de sentido, y desde allí, nuevas cosmovisiones sobre la historia y la inclusión de narrativas cotidianas, silenciadas y "escondidas". Esto se relaciona con lo que Néstor Míguez (2001, pp. 90-93) nos advierte respecto a que no necesitamos un canon de la liberación sino la liberación del canon.

En otros términos, una hermenéutica liberadora en torno al texto bíblico reside en su potencial inherente para provocar interpretaciones a partir de su heterogénea composición literaria, contextual e histórica, que posibilita hoy también la resignifición de experiencias e historias. Esto significa ir más allá de un simple uso político de los textos bíblicos, sumiendo su interpretación a la conexión con ciertos marcos ideológicos predeterminados, como han hecho las TL. Por el contrario, la proyección política del texto bíblico se deposita en ofrecer un espacio compuesto por una pluralidad de trayectorias teológicas (reflejadas a su vez en una diversidad de historias y experiencias concretas) que se orientan en la búsqueda de "la verdad", en tanto especialidad vacía (Badiou), circunscrita en el dogma como nominación acontecimental y espacio límite entre lo plural y lo particular. En otras palabras, el uso de los textos bíblicos nos muestra cómo la identidad reflejada en una tradición religiosa -la judeo-cristiana en este caso- puede ser releída hacia una superación de lo particular que permita la apertura de un espacio de acción histórica, que desde la búsqueda de la verdad amplíe los campos de significación política.

\section{Una crítica hermenéutica hacia dentro de la TL}

Lo desarrollado hasta aquí nos da algunos elementos para remarcar una vez más sobre la necesidad de que la TL realice una crítica hermenéutica hacia sí misma desde sus mismos ejes metodológicos. Nos referimos más específicamente a que la importancia de su metodología reside en la apertura de más discursos, en la inclusión de otras 
cosmovisiones y en una deconstrucción mas profunda de la noción de Dios. Dicho de forma más narrativa, Lisa Isherwood (2013, p.14) afirma que "el rol de los teólogos no es subsanar la ruptura que creó la encarnación divina; más bien, nuestro rol es continuar la discontinuidad".

En esta línea, Marcella Althaus-Reid sostiene que la importancia de la TL como método se encuentra en ser un marco de crítica a los fundamentos epistemológicos del quehacer teologal. En sus palabras (Althaus-Reid, 22):

La perturbación de la normalidad en la teología de la liberación necesita ser
considerada como fundamento de una praxis desde la cual no sólo develaremos
las normalidades construidas en los procesos de formación ideológica en una
reflexión teo-social, sino también una práctica a través de la cual participar de
un trabajo teológico liberador. Es una praxis que entiende que Dios es siempre
una categoría de lo posible, que Dios no representa el límite de lo divino, y que
el pasaje de lo teológico no es continuidad sino disconformidad.

Vemos aquí que el valor de la hermenéutica en la TL emana de su capacidad perturbadora de fundamentos. No en asumir un concepto de historia, sino en desplegar la teología en la infinidad de complejos escenarios históricos. No en entronar una sola categoría de sujeto sino en incluir a todo agente en una situación de opresión como fractura liberadora del estatus quo. No en partir de un Ente Absoluto Liberador sino de liberar la misma noción de lo divino hacia un Misterio que irrumpa las representaciones establecidas, tensionando las fronteras de sentido hegemónicas. Este poder hermenéutico es el que la TL requiere asumir desde una radicalización de sus ejes metodológicos, en vistas de pluralizar discursos, sujetos y teologías.

\section{Conclusiones}

En este artículo hemos argumentado que uno de los elementos más importantes desarrollados por la TL ha sido su método, cuya articulación y ejes han permitido que su propuesta teológica perdure a lo largo de la historia, y posibilite la emergencia de un conjunto de expresiones y discursividades. De todas formas, muchos/as han identificado que algunos de estos elementos -más específicamente, los discursos particulares desarrollados a partir de dichos ejes- evidencian reduccionismos que imposibilitan radicalizar las implicancias teológicas, socio-políticas y culturales de dicho método, y su apertura hacia otros sujetos, otras cosmovisiones y otras teologías. 
Por ello, la necesidad de construir nuevas sensibilidades, es decir, nuevos acercamientos a los procesos reales que se dan en tres epicentros de este método y sus respectivas mediaciones hermenéuticas: el lugar de los sujetos, los procesos históricos y las maneras de definir a Dios. Para lograr esta empresa, hemos desarrollado muy brevemente cuatro temas centrales: la necesidad de pensar en una ontología hermenéutica (que inscriba los procesos de resignificación e interpretación, no desde una hermenéutica tomada sólo como un objeto o metodología sino como un marco ontológico propio del quehacer teologal); la importancia de la noción de alteridad y trascendencia (marcos que permiten abrirse a la pluralidad, la diversidad y lo heterogéneo, no como elementos descriptivos y cuantitativos sino como constitutivos del ontos teológico, en vistas de incluir nuevos sujetos, cosmovisiones y teologías); la relevancia de una teo-poética como crítica poscolonial (es decir, una teología que parta desde una sensibilidad sobre los procesos y gestos del cuerpo, lo artístico y lo poético como espacios donde se inscriben tanto la ambivalencia de los contextos como los modos creativos a partir de los cuales los sujetos combaten y resisten en su cotidianeidad los embates de las lógicas opresoras que imponen lo normativo y naturalizado); y por último, una hermenéutica acontecimental del texto bíblico (que asuma la pluralidad de historias, experiencias, relatos y sentidos dentro del texto, en pos de la construcción de un espacio acontecimental donde la potencialidad hermenéutica de las Escrituras se ubique en su convocatoria de posibles e incontables sentidos de la revelación divina como marco de liberación de discursos, prácticas y cosmovisiones).

Apelar a estar nuevas sensibilidades esta lejos de la difundida aseveración sobre la muerte de la TL. Por el contrario, su método aún tiene mucho para aportar al quehacer teológico y las lecturas críticas sobre las situaciones de opresión en América Latina y el resto del mundo. La teología desde la propuesta de la TL debe pasar del paradigma de la reflexión a partir de una crítica suturada sobre una praxis en términos absolutos, a una sensibilidad que tome todos los elementos constitutivos del sujeto, de la historia, del cosmos, de las posibilidades de revelación divina y los diversos modos de llegar al texto bíblico, en pos de construir una pluralidad de prácticas, discursos, cosmovisiones y resistencias. 


\section{Bibliografía}

ALTHAUS-REID, M. "From Liberation Theology to Indecent Theology. The Trouble of Normality in Theology". En: PETRELLA, I., ed., Latin American Liberation Theology. The Next Generation, Maryknoll: Orbis Book, 2005, p.20-38

ALVES, R. Hijos del mañana. Salamanca: Sígueme, 1976

La teología como juego. Buenos Aires: La Aurora, 1982

ASSMANN, H. "Por una teología humanamente saludable. Fragmentos de memoria personal”. En: SUSIN, L.S. El mar se abrió. Treinta años de teología en América Latina. Santander: Sal Terrae, 2000, p.108-122

. "Apuntes sobre el tema del sujeto". En: DUQUE, J., org., Perfiles teológicos para un nuevo milenio. San José: DEI, 2004, p.116-146

BAHBAH, H. El lugar de la cultura. Buenos Aires: Manantial, 2002

BADIOU, A. El ser y el acontecimiento. Buenos Aires: Manantial, 2007

BOFF, C. Teología de lo político. Salamanca: Ediciones Sígueme, 1980

CAPUTO, J. “Hermenéutica espectral: sobre la debilidad de Dios y la teología del acontecimiento" En: CAPUTO, J. y VATTIMO, G. Después de la muerte de Dios. Conversaciones sobre religión, política y cultura. Buenos Aires: Paidós, 2010, p.75-134

CÉSPEDES, G. "Nuevos hilos para un nuevo tejido. A 50 años del Vaticano II y 40 años de la Teología Latinoamericana y Caribeña" En: BIGHENTI, A. y HERMANO, R., Orgs. La teología de la Liberación en Prospectiva. Congreso Continental de Teología. Santiago de Chile: Ediciones Universidad Católica Silva Enrique, 2014, p.37-70

DELEUZE, G. Lógica del sentido. Barcelona: Planeta-Agostini, 1994

Diferencia y repetición. Madrid: Editora Nacional, 2002

DERRIDA, J. Decir el acontecimiento, ¿es posible? España: Arena Libros, 2013

ELLAQURÍA, I. "Historicidad de la salvación cristiana" en ELLAQUIRÍA, I y SOBRINO, J., comps., Mysterium Liberationis, Tomo I, San Salvador: UCA Editores, 1993, p.328-329

.Filosofía de la realidad histórica. San Salvador: UCA Editores, 2007

GABILONDO, A. La vuelta del otro. Diferencia, identidad, alteridad. Madrid: Trotta, 2001

GEBARA, I. Intuiciones ecofeministas. Ensayo para repensar el conocimiento y la religión. Madrid: Trotta, 2000 
GONZÁLEZ, A. "El significado filosófico de la Teología de la liberación". En: COMBLIN, J., GONZÁLEZ FAUS, J., SOBRINO, J. Cambio social y pensamiento cristiano en América Latina. Madrid: Trotta, 1993, p.145-160

GUTTIÉRREZ, G. Teología de la liberación. Perspectivas. Lima: CEP, 1986 . ¿Dónde dormirán los pobres? Lima: CEP, 2002

HARMAN, G. Hacia el realismo especulativo. Ensayos y conferencias. Buenos Aires: Caja Negra, 2015

HINKELAMMERT, F. El grito del sujeto. San José: DEI, 1998

ISHERWOOD, L. y HARRIS, D. Radical Otherness. Sociological and Theological Approaches. Durham: ACRUMEN, 2013

KELLER, C. Face of the Deep. A theology of Becoming. London and New York: Routledge, 2003

LATOUR, B. Reensamblar lo social. Una introducción a la teoría del actor-red. Buenos Aires: Manantial, 2005

LEAVEY, J. "Four protocols: Derrida, his deconstruction”. EN: Semeia, vol. 23, 1982, pp. 42-57

LOPRESTI, M. "Poiesis, Fides, et Ratio in the Absence of Relativism" En: FABER, R. y FACKENTHAR, eds., Theopoetic Folds. Philosophizing Multifariousness. New York: Fordham University Press, 2013, p.81-96

MALDONADO-TORRES, N. "Liberation Theology and the Search for a Lost Paradigm. From Radical Orthodoxy to Radical Diversity" En: PETRELLA, I., ed., Latin American Liberation Theology. The Next Generation, Maryknoll: Orbis Book, 2005, p.39-61

MATTERA, M.C., "La belleza de un diálogo posible" En: DE POLUMBO, C y QUELAS, J. Belleza que hiere. Reflexiones sobre Literatura, Estética y Teología. Buenos Aires: Agape Libros, 2010, p.243-287

MCFAGUE, S. Modelos de Dios. Teología para una era ecológica y nuclear. Santander: Sal Terrae, 1994

MIGUEZ, N. "Lectura latinoamericana de la Biblia. Experiencias y desafíos" En: Cuadernos de teología, Vol. XX, 2001, p. 90-93

PANOTTO, N. Hacia una teología del sujeto político. San José: UNA, 2012 - "Heterotopías, nomadismos e identidades populares Una relectura del concepto de pueblo desde el relato del Éxodo en las teologías de la liberación" En Horizontes Decoloniales, Volumen 1, No. 1, 2015, p.164-195.

De juegos que hablan de Dios. Hacia una teología desde la niñez latinoamericana. Quito: SBU, 2016a

Religión, política y poscolonialidad en América Latina. Hacia una teología posfundacional de lo público. Buenos Aires: Miño\&Davila, 2016b 
RIVERA, M. The Touch of Trascendence. A Postcolonial Theology of God.

Louisville-London: Westminster John Knox Press, 2007

SEGUNDO, Liberación de la teología. Buenos Aires: Ediciones Carlos Lohlé, 1975

.Teología abierta, Tomo III, Barcelona: Ediciones Cristiandad, 1983

El dogma que libera. Santander. Sal Terrae, 1989

SCHNEIDER, L. Beyond Monotheism. A Theology of Multiplicity. London and New York: Routledge, 2008

SUNG, J.M. Sujeto y sociedades complejas. San José: DEI, 2005

TRÍAS, E. “La superación de la metafísica y el pensamiento del límite”. En: VATTIMO, G., comp. La secularización de la Filosofía. Hermenéutica y posmodernidad, Buenos Aires: Gedisa Ediciones, 1994, p.283-296

VATTIMO, G. Las aventuras de la diferencia. Pensar después de Nietzsche y Heidegger. Barcelona: Península, 1986

VATTIMO, G. Y ZABALA, S. Comunismo hermenéutico. De Heidegger a Marx. Barcelona: Herder, 2012

VIGIL, J. La opción por los pobres. Santander: Sal Terrae, 1991

YOUNTAE, A. The Decolonial Abyss. Mysticism and Cosmopolitics from the Ruins. New York: Fordham University Press, 2016

ZAMBRANO, M. Notas de un método. Madrid: Tecnos, 2011

ŽIŽEK, S. Acontecimiento. Madrid: Sextopiso, 2015 